\title{
LA SIMULTANEIDAD ESPACIAL EN LA POESÍA CUBISTA DE GERARDO DIEGO ${ }^{1}$
}

\author{
M. a Ángeles HERMOSILLA ÁLVAREZ \\ Universidad de Córdoba
}

$\mathrm{H}$ ablar de la posibilidad de trasladar un determinado código pictórico a otro literario, verbal, conlleva la consideración de que se trata de dos sistemas de signos con características propias. Y, en efecto, desde Lessing sabemos que los signos visuales pertenecen al arte del espacio, en el que varios elementos pueden presentarse simultáneamente, y, además, son proclives a la «mímesis»; los verbales, en cambio, poseen una dimensión temporal, en la que, como sostenía Jakobson, se da una determinada sucesión, y sus elementos se integran en una estructura (Colvile, 1977: 35).

Estas peculiaridades -corroboradas por nuestra propia experiencia: para ver cómo están constituidos los objetos de nuestro entorno no es necesario aparentemente elaborar razonamientos, pensar- han contribuido a disociar los hechos perceptivos y los de pensamiento como dos actividades psíquicas heterogéneas: la primera, fuente del mundo sensible, de la apariencia falsa y cambiante de las cosas; la segunda, instrumento de construcción racional de la realidad con los datos que esta le proporciona.

Sin embargo, existen otras líneas filosóficas que, si bien no defienden la identidad de las dos actividades, sí señalan una continuidad entre las dos (Kanizsa, 1986: 281). En esta línea se sitúan, por un lado, los representantes de la Gestalt alemana, quienes sostienen que las leyes de organización válidas para la percepción también actúan para el pensamiento, que genera el discurso verbal, una idea que hemos desarrollado en un trabajo anterior (Hermosilla Álvarez, M. Á., 2011). Por otro, los cognitivistas mantienen que los procesos perceptivos se desarrollan según parámetros que obedecen a las mismas reglas que los procesos mentales, si bien a menudo de modo inconsciente.

Así pues, los hechos perceptivos y conceptuales, aunque se manifiesten en códigos diferentes, son formas distintas de un mismo proceso de cognición, que se revela muy evidente en el movimiento cubista. Y ello por dos razones: primeramente, porque, aunque desde el Laocoonte

\footnotetext{
${ }^{1}$ Una primera versión de este trabajo fue publicada con el título «La transcription de la simultanéité spatiale dans la poésie cubiste de Gerardo Diego» (2000), en Prudon, M., coord., Peinture et écriture 3. Frontières éclatées. Paris, La Différence (UNESCO), pp. 179-193.
} 
232 Tropelías. Revista de Teoría de la Literatura y Literatura Comparada, número extraordinario 2 (2017) M. ángeles Hermosilla Álvarez

(1766) de Lessing, se han estudiado en diferentes parcelas las manifestaciones pictóricas y literarias, en realidad el cubismo suponía una visión del arte, una teoría estética de la que participaban por igual pintores como Picasso, Braque o Juan Gris y poetas como Apollinaire, Reverdy, Huidobro o Gerardo Diego, entre los cuales con frecuencia existía una estrecha amistad, como la que mantuvo el poeta santanderino con Huidobro desde 1921 (De Costa, 1993: 12) y con Juan Gris, que propiciaba el intercambio de ideas. Los poetas veían la aplicación de la técnica cubista a los cuadros y, siguiendo el ejemplo de Mallarmé en Un coup de dés, la practicaban en sus creaciones; y los pintores, en algunos de los cuales predomina también el carácter lírico -como en Juan Gris (Kahnweiler, 1946: 244)- reflexionan y escriben por primera vez sobre este arte (Gleizes y Metzinger, 1912) o incorporan la letra al cuadro (Hermosilla Álvarez, C., 1990).

En segundo término, por la propia esencia de este movimiento artístico, que, sobre todo en el cubismo sintético, no toma como referencia la realidad, sino que procede por intuición global, una especie de «reducción eidética» (Husserl, 1997: 55) que crea un nuevo objeto sin ninguna particularidad accidental pero con todos sus predicados esenciales (Hadermann, 1984: 95). En definitiva, lejos de imitar los objetos de la realidad, como correspondería a un arte visual, deconstruye los objetos para construirlos de nuevo, dando lugar al cuadro-objeto (De Micheli, 1988: 211 y 215).

De esta forma, lo visual y lo conceptual formar parte, en el cubismo, de una misma actividad cognoscitiva -en la medida en que por conocimiento en arte no se entiende la transmisión de información, sino la representación mental de un mundo vivido como real (Hermosilla Álvarez, M.Á., 2011: 28)- que tiene una vertiente pictórica y otra literaria en estrecha interrelación, unas conexiones que trataremos de descubrir en el caso de Gerardo Diego. Se trata de una cuestión a la que ya nos acercamos con la ilustración de la teoría cubista en un poema de Diego, al que sirve como referencia un cuadro de Juan Gris (Hermosilla Álvarez, M. Á., 1996: 163-172).

Ahora nuestro objetivo es aislar, con carácter más general, ciertos procedimientos literarios que suponen una transposición de los elementos plásticos empleados por los pintores cubistas, y más concretamente por el cubismo sintético de Juan $\mathrm{Gris}^{2}$, en la dos obras que mejor responden a estos postulados estéticos: Imagen (1922) y, especialmente, Manual de espumas (1924), libro de madurez en el que, en palabras del mismo autor, quiso hacer una transposición poética de lo que entonces era el cubismo (Alonso, 1969: 236).

Esta corriente artística supone una visión subjetiva de la naturaleza (Golding, 1993: 32), por la que el artista pinta el mundo no a partir de su observación, sino del conocimiento que posee de él (Golding, 1993: 37; Guiney, 1966: 14 y 72), dando paso a todo su impulso creador. En esta línea, la poesía creacionista de Vicente Huidobro, muy ligada al cubismo de Juan Gris (Cano Ballesta, 1998: 156), propugnaba «crear un poema como la naturaleza crea un árbol» (Diego, 1974: 45). Nos

\footnotetext{
${ }^{2}$ Vid., acerca del cubismo de Gris y Diego, aparte de nuestro trabajo (Hermosilla Álvarez, M. Á., 1996), Cano Ballesta (1998: 153-172). Juan Gris influirá a través de su amistad con Diego, Larrea y Huidobro, en los poetas jóvenes de su época, incluso más que en los pintores (Id.: 157).
} 
hallamos ante una obra en la que no se da ya una «representación» sino una «presentación» de una realidad nueva, construida con elementos dispares que convergen, gracias a una tarea de montaje, en una imagen total y simultánea con múltiples facetas (Hadermann, 1984: 944 y 945).

Es cierto que esta simultaneidad no sólo es una característica del cubismo, sino que está presente en el futurismo ${ }^{3}$ e incluso tal vez fuera este movimiento, preocupado por la rapidez de la percepción, el que abriera el camino a una forma de ver basada en la captación instantánea (Verhesen, 1984: 806), pero el cubismo es más específicamente un arte de montaje. Además, la simultaneidad cubista es estática, mientras que la futurista es de carácter dinámico, lo que se refleja en la elección de los temas: trenes, caballos, aviones o batallas (Hadermann, 1984: 945).

Así pues, se abandona la perspectiva y, en el cubismo sintético especialmente, los elementos de la nueva obra se presentan, merced a la técnica del «collage», yuxtapuestos en un espacio vertical, casi plano (De Micheli, 1988: 213-215). En literatura la imagen se convierte en la máxima expresión del espíritu creador, pero la imagen creacionista no surge de la simple comparación de dos realidades más o menos próximas, sino de la asociación de dos nociones alejadas entre sí, según proponía Pierre Reverdy (1918), con lo que se abre la vía a la imagen surrealista. Es lo que Juan Gris, cuyo lirismo ya hemos señalado, denominaba «rima» (Kahnweiler, 1946: 247 y 248): la metáfora acerca al perceptor dos objetos diferentes, o bien dos formas que no son iguales se repiten como rimas (el mantel y el cielo; el casco de una embarcación y las cuerdas de la guitarra), como apuntábamos en nuestro trabajo (Hermosilla Álvarez, M. Á., 1996: 170 y 171). Así se produce el «arte de síntesis», en el que las formas de los objetos son recortadas en facetas simples sin espesor y permitiendo la transparencia. Por otra parte, las formas imponen ciertos ejes dinámicos y tienden a determinar figuras geométricas, con frecuencia en círculo, cónicas o cilíndricas, como quería Cézanne (De Micheli, 1988: 156-159; Golding, 1993: 194), y tal como aparece también en Juan Gris, en un intento de precisión que rechazaba lo anecdótico y lo superficial para aprehender el volumen de las cosas, su esencia geométrica (Cano Ballesta, 1998: 156-159).

Estas características se manifiestan en la poesía de Diego en un léxico de gran sencillez, con predominio del sustantivo (la palabra que designa la sustancia): guitarra, mar, mesa, casas, sol, plato, frutas, etc. y algunos verbos, utilizados sobre todo en presente (tiempo que intenta traducir la simultaneidad estática cubista). Sintácticamente los textos se caracterizan por la ausencia de puntuación, que proporciona un carácter abierto a la obra, el escaso empleo de la subordinación y el uso de frecuentes repeticiones, reforzadas a menudo por la rima consonante. Asimismo se juego con el silencio y el blanco de la página, lo que da lugar a la desarticulación de la sintaxis y la dispersión tipográfica, donde las letras se convierten en líneas pictóricas que tratan de dibujar el objeto evocado, potenciando el valor gráfico del verso (López Martínez, 1988: 231-251 y 1989: 145-170). Junto al ritmo fónico, pues, aparece el ritmo gráfico, por el cual la línea poética parece acomodarse

\footnotetext{
${ }^{3}$ Incluso se ha pensado que el cubismo y el futurismo, junto al dadaísmo, participan los tres de un solo movimiento más amplio, como señaló A. Breton (Orlandi, 1982: 67-68).
} 
plásticamente a lo que se comunica en el verso. Este, por su parte, crea una realidad que, gracias al título (muy habitual en los cuadros cubistas) se muestra unitaria y coherente.

De este modo en el poema «Tren», perteneciente a Imagen $^{4}$, se reproducen los raíles de la vía férrea y las líneas poéticas sugieren el sentido de los versos:

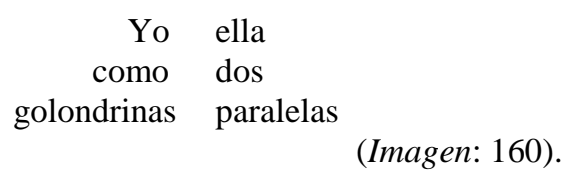

Y más adelante la línea poética escalonada parece simular el acto de depositarse las hojas:

El olvido

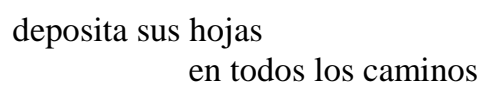

(Ibíd.)

O bien la caída de la lluvia:

Agitando los árboles llueven

llueven silencios ahorcados de las ramas

(Ibíd.)

En el poema «Gesta» las líneas versales también reproducen el contenido textual (el acueducto):

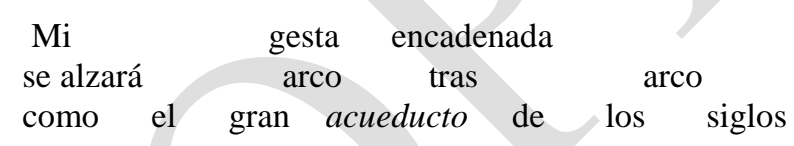

(Imagen: 155)

Por otro lado, en «Círculo», que, inspirado en el ideograma de Apollinaire «La cravate y la montre», trata de plasmar la forma circular de la corbata, los versos quinto, sexto y séptimo expresan gráficamente el goteo de la sangre, mientras que la línea fluyente que une los dos primeros versos prolonga el contenido semántico:

\section{CÍRCULO}

Este recóndito fastidio

anida todos los años en mi oído

Y este motor que nada mueve

siempre zumbando su estribillo agreste

Gota a gota

las abejas

van quemando el zumo de mis venas

\footnotetext{
${ }^{4}$ Seguiremos la edición de Imagen (Diego, 1990) realizada por José Luis Bernal. En lo sucesivo, tras el texto se citará Imagen y página.
} 


\author{
Sangre de ríos \\ discurre por mi lecho
}

Curada de su parálisis

ha vuelto a andar la vida

Mi corbata

rueda con su rumor de catarata

(Imagen: 175)

Pero tal vez sea en el siguiente poema, donde el valor gráfico que representa un columpio a base de la línea fragmentada, repetida simétricamente, al igual que la línea con sangría, parece acompañar más claramente al ritmo fónico, que, por la repetición de SI-NO, sugiere el movimiento pendular del columpio:

\title{
COLUMPIO
}

A caballo en el quicio del mundo un soñador jugaba al sí y al no

Las lluvias de colores emigraban al país de los amores

Bandadas de flores

Flores de sí Flores de no

Cuchillos en el aire que le rasgan las carnes forman un puente

Sí

Cabalga el soñador

Pájaros arlequines

cantan el sí

cantan el no

(Imagen: 191)

Un similar movimiento de vaivén observamos en el poema «Canción de cuna», de Manual de espumas $^{5}$, en el que la estructura circular basada en versos de arte menor (heptasílabos), de arte mayor y luego nuevamente versos de siete sílabas, junto al léxico («viento de ida y vuelta», «la noria seguirá») y las repeticiones parecen plasmar el acto de mecer la cuna:

\section{CANCIÓN DE CUNA}

El viento de ida y vuelta

A Céline Arnauld

y el abanico en calma

El tren ha muerto en la estación de enfrente y mi pañuelo cuelga de la rama más alta

\footnotetext{
${ }^{5}$ Utilizaremos la edición de Manual de espumas. Versos humanos(Diego, 1986) de Milagros Arizmendi. Citaremos por Manual y página.
} 
236 Tropelías. Revista de Teoría de la Literatura y Literatura Comparada, número extraordinario 2 (2017) M. Ángeles Hermosilla Álvarez

Dejad que pasen los arroyos

Dejad que vuelen mis lágrimas

No permitáis en cambio que se acerquen

las ventanas lejanas

La noria continuará

lavando los pañales

y la playa acunando

los náufragos triviales

(Manual: 100)

En otras ocasiones la línea fragmentada intenta mostrar la ausencia o el vacío:

Nadie Nadie (Imagen: 168)

La expresión entrecortada de la súplica:

Ay Señor Señor Señor (Imagen: 200)

El lapso de tiempo entre dos días:

$$
\text { Ayer } \quad \text { Mañana (Manual: 77) }
$$

La forma alargada del tranvía:

Y tú manso tranvía (Manual: 79)

O bien el espacio recorrido por el poeta en su peculiar pastoreo:

Yo pastor de bulevares (Manual: 108)

Un último ejemplo de Manual de espumas nos presenta una composición formada por una tirada larga de versos, cortos en su mayoría, que evoca el espacio vertical del cuadro cubista, al tiempo que refleja la altura de edificio al que se alude en el título:

\section{HOTEL}

\section{A Alfonso Reyes}

La frente sin laurel y sin sombrero

y el corazón para el color de moda

A cada nuevo baile

el reloj pierde el paso

El viento nace de tu manto

y acaricia las frutas

desgajadas del tango

Vendimia de las nubes pisoteadas

y de las músicas amadas

Y el ritmo de los suspiros

hace girar las parejas

y acercarse a nosotros el vestíbulo

Cerrando bien los ojos

pienso en las travesías

y en los hoteles que anclan la quilla envejecida

Son las islas trasatlánticas 


\author{
donde crecen los mástiles \\ y dan frutos de invierno \\ donde los tísicos respiran \\ el oxígeno tierno \\ Al izar la bandera \\ esparce por los aires \\ plumas de cazadores y aromas de maderas \\ El otoño marchita corbatas y sombreros \\ y de la alfombra brota la primavera \\ Ruleta del azar y de las temporadas \\ Los jockeys de la moda sortean sus colores \\ $\mathrm{Y}$ aquel que pierde la jugada \\ tiene derecho a un vals para mudar de amores \\ Yo amo el buen tiempo y el hotel \\ y yo he visto mujeres de rizos calcinados \\ Las olas las rociaban de espumas de cocktail
}

Pero, con ser relevantes el ritmo gráfico, no podemos pasar por alto el ritmo fónico, al que contribuye en buena medida la repetición de sílabas, palabras o frases. Igual que el pintor cubista disponiendo su cuadro según un conjunto de cubos o círculos se apodera del espacio, el poeta, con las reiteraciones sonoras, realiza una primera organización del texto que le indica, como señala Paul Hadermann (1984: 948), el camino que ha de seguir, y se aproxima a la técnica cubista (Id.: 949950). Así, la rima, casi siempre consonante, otorga un carácter abierto y dinámico al texto que sugiere el movimiento circular (el cilindro, el cono) de los cubistas, al mismo tiempo que sirve para unir dos realidades distintas, superando la linealidad del discurso verbal, que se acerca de este modo al pictórico, donde podemos percibir simultáneamente dos formas o dos acciones diferentes: Hermanos-manos (Imagen: 121), pareja-abeja (Ibíd), andróginos-misóginos (Ibíd), balas-alas (Ibíd), cera-era (Id: 124), espiga-amiga (Ibíd), cuna-luna (Id: 130), colores-amores (Id: 191), sortija-hija (Id: 204), rosas-cosas (Manual: 77), limón-canción (Ibíd), mapa-capa (Id: 82), corderos-luceros (Id: 97), grillo-organillo (Ibíd), gallo-caballo (Ibíd), carretera-ladera-primavera (Id: 104), meta-cometa (Id: 107), estrella-botella (Id: 108), se estremecen-parecen-florecen (Imagen: 105), se deshoja-se sonroja (Id: 196), levantan-cantan (Manual: 88), etc.

La rima con frecuencia da origen a la figura de la paronomasia, que, por otra parte, también puede presentarse en el inicio o en el centro del verso. En cualquier caso, se trata de un recurso donde términos con significados dispares se unen por su semejanza fónica provocando asociaciones inéditas que reflejan la superposición de planos del cuadro cubista (Hadermann, 1984: 948 y 949). Veamos algunos casos: «Como una mariposa,/el sol se posa» (Imagen: 109), «Qué pocos cantos sabe el ruiseñor [...] Ay Señor Señor Señor» (Id: 200), «Muerden las estrellas de los hielos / y hay una única virgen / a lo largo del cielo» (Id: 201), «Y un sabor de jabón en el remanso» (Manual: 88) donde los términos parónimos dan lugar a una sinestesia, procedimiento que nos habla asimismo del cruce de sensaciones distintas-, «El reloj de los vientos [...] y hace juegos de agua en los advientos» (Id: 91). 
Otras veces el contexto suscita en el lector el vocablo parónimo, que aflora como un caso de intertextualidad lingüística de gran poder evocador: «Y doncellas sin novio / me esposan las manos / con un rosario póstumo de versos» (Imagen: 156) -que arrastra el términos besos-, «Pero el gran caserón está desierto» (Id: 190) -evocador de corazón-, «Son las islas trasatlánticas / donde crecen los mástiles / y dan fruto de invierno» (Manual: 98) -que sugiere dátiles- o «Es como un solo de jardín entre el murmullo de los prados» (Id: 121), donde subyace el intertexto violín.

Relacionado con la paronomasia se encuentra el calambur, otro procedimiento que refleja la yuxtaposición del espacio cubista: «Ostenta / la cornamenta / de las cabras de Malta. Irónico signo / maligno» (Imagen: 128) -donde la unión de la sílaba inicial de Malta y el término signo confluyen en maligno-, o el título «Rebaño» (Id: 190), que por la acción de mojar que conlleva la lluvia de la que se habla en el poema bien pudiera leerse Re baño. En Manual de espumas hallamos también algunos ejemplos: «El viento nace de tu manto / y acaricia las frutas / desgajadas del tango» (Manual: 98), en el que la primera sílaba de manto y la última de tango forman el nombre de la fruta a la que se alude en estos versos: mango. $\mathrm{O}$ «Condúceme a tu establo / y sácame del pozo en que te hablo» (Id: 79), donde el yo lírico se dirige al tranvía para que le conduzca al establo, calambur construido por los términos estación (implícito en el texto) y hablo.

Un mecanismo generador de efectos muy similares a los que acabamos de ver es la dilogía que, aunque no muy frecuente en Gerardo Diego, ofrece algún ejemplo donde la polisemia de los términos permite la referencia a varias nociones: «Anidaba en sus ojos / el ave maría» (Imagen: 157). Aquí el significado de «anidar» justifica que ave se entienda como «pájaro» pero, en este contexto, alude sobre todo a la oración de la Virgen María. Del mismo modo «Se ha callado la rueda en mi bemol / alrededor del pozo / por donde sube el agua y baja el sol» (Manual: 92) permite interpretar dilógicamente sol: como astro y como término del campo musical, una alusión que introduce «bemol» y que continúa «pozo», posible referencia a la guitarra, que se escribe en clave de sol.

Mucho más habituales son sin duda las figuras de repetición como anáforas y paralelismos, que, en opinión de P. Hadermann (1984: 949-950), confieren unidad al poema y «font penser à ces pans plus larges ou ces droites plus accusées qui, chez Gris, Braque ou Picasso, affirment les axes majeurs du tableau». He aquí una muestra: «Dancemos al coro de antorchas. / Dancemos en el rito druídico» (Imagen: 136), «Viva la moza. Viva la Juana. / Viva el espliego y la mejorana» (Id: 137), «Jugamos a las cuatro esquinas / Jugamos a la gallina ciega» (Id: 138), «Nadie llegó a su fin / Nadie sabe que el cielo es un jardín» (Id: 173), «Mujer densa de horas / [...] / Mujer cultivadora / [...] / Mujer en donde nacen las abejas / [...] / Mujer puntual como la luna llena» (Manual: 91), «Dejad que pasen los arroyos / Dejad que vuelen mis lágrimas» (Id: 100).

En algunos momentos el paralelismo puede convertirse en estribillo: «La sombra verde de mi amor / La sombra verde de mi amor» (Manual: 77).

También encontramos otras figuras de repetición -a veces utilizadas junto a las anteriorescomo la anadiplosis: «Humo de estrellas. Humo de hogueras. / Hogueras en el cielo y en la tierra» (Imagen: 136), «Agitando los árboles / llueven / llueven silencios» (Id: 166), «Quién mueve nuestras 
ramas / nuestras ramas elásticas / Quién agita las noches apiñadas» (Id: 176), «Rápido / rápido como un viaducto» (Id: 177), «Tu vara florezca en todos los tejados / tejados olvidados» (Manual: 80); la epanadiplosis: «Canta cometa canta» (Manual: 81); o la epanalepsis: «Sangre Sangre de aurora» (Imagen: 166), «Dame una rosa una rosa» (Id: 198). Y, en definitiva, reiteraciones de palabras o frases que recorriendo el poema, lo vertebran en una estructura. Así, por ejemplo, la repetición en el poema «Rosa mística» (Imagen: 157), del sintagma «era ella» actúa como el eco de la letanía mariana de la que forman parte las palabras del título. De igual modo la estructura «verbo dar más complemento», que se repite tres veces con una ligera variante («Dame una rosa» [...] «Dame la luna» [...] «Dámela» en «Jaculatoria» (Id: 198), evoca el tono de la plegaria a la que se alude asimismo en el título. O la animación, reiterada en tono imperativo, al baile de «Danzar / Cautivos del bar», que se cierra con la frase exclamativa «Hurra / Cautivos del bar» perteneciente al poema «Paraíso» (Manual: 85), parece dibujar el movimiento circular de la danza.

Por último, para concluir con los procedimientos que determinan el ritmo fónico circular, generador de las formas cubistas, hay que hablar de las isotopías fónicas, mecanismos formales que contribuyen a sugerir o subrayar el contenido semántico de los versos. Eso sucede con la aliteración de la vibrante tensa a lo largo del poema «Ría» (Inagen: 111), que se intensifica en el centro («Dos gaviotas turistas / nos traen el mar a la tierra / y ría arriba se pierden») y el final de la composición («Un remolino de hélice / nos va a tragar... Rema, Rema»); la repetición de nasales con la que finaliza «Piscis» (Id: 130): «Dame la mano, hermana. / Vamos a bailar la sardana», intenta plasmar la danza; de líquidas, especialmente ele, en «Géminis» (Id: 121): «El águila bicéfala vuela / invulnerable a las balas. / Al alma le nacen dos alas / y persigue al alma gemela», evocadora del aleteo del águila; de la sibilante en «Escorpio» (Id: 126), que se refuerza con el ritmo gráfico producido por la disposición versal en zig-zag:

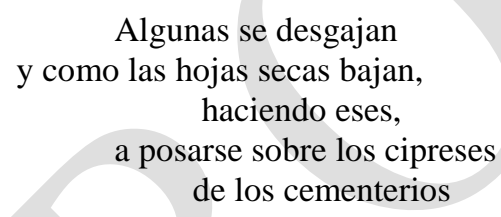

Algo similar se produce en el siguiente ejemplo de «Canción fluvial» (Manual: 88), donde la aliteración de erre y una tipografía que tiende al movimiento circular sugiere la acción de rodar:

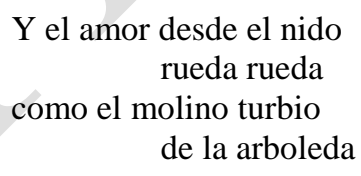

Por otra parte, en ciertos momentos las isotopías fónicas dan lugar a onomatopeyas que tratan de reflejar lo que se nos dice en el plano semántico: «Arcos de flores. El tamboril / -viva el espliegorepica cri cri. / Campanero, toca las campanas [...]. Humo, Amapolas. Tin-tan. Tin-tan» (Imagen: 137). 
En los siguientes versos la aliteración de erres y dentales parecen recoger fónicamente el movimiento circular, presente en el título y en el aspecto tipográfico del poema, que conlleva la acción de colocarse la corbata y el posterior descenso de la cascada en que, figuradamente, se presenta al caer sobre el pecho: «Mi corbata / rueda con su rumor de catarata» (Imagen, 175). Y en este último caso las isotopías recuerdan el sonido del acero y la cuchillada final: «Cuchillos en el aire / que le rasgan las carnes» (Id: 191).

Ahora bien, la mejor expresión del cubismo sintético en literatura es la imagen múltiple, aquella que se presta a varias interpretaciones (De Costa, 1993: 18) y se inspira en el collage y la superposición de planos. Es una forma de transcribir el simultaneísmo visual al código discursivo de la poesía. Así pues, cuando el poeta escribe: «La abuela junto al tiempo / rezaba su rosario de nietos» (Imagen: 149) yuxtapone distintas imágenes: la abuela, tan anciana como el tiempo, cuenta a sus nietos, tan numerosos como las bolitas [«cuentas», intertexto que ha generado la interpretación de «contar» nietos] de su rosario. Del mismo modo procede en: «Y a mi alborotado ruiseñor / lo encerré en la jaula / y oprimí el botón del ascensor» (Id: 153), que puede entenderse así: yo, que llevo un ruiseñor que canta (noción subrayada por las isotopías de la vibrante tensa), subo en un ascensor donde me veo como en una jaula.

Y en los siguientes versos, cuyo significado se expresa también gráficamente por la línea poética escalonada:

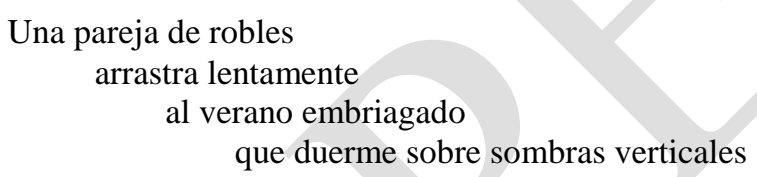

(Id: 178)

Es decir, una pareja de robles, como si de una pareja de guardias se tratara, arrastra al verano que, igual que un hombre embriagado, busca, para dormir, las sombras de los árboles.

La misma técnica de acumulación de imágenes se da en «Hotel», de Manual de espumas: «El otoño marchita corbatas y sombreros / y de la alfombra brota la primavera» (Manual: 99), donde se habla del otoño que hace caer las hojas secas en las corbatas y sombreros, mientras que del suelo brotará como una alfombra la primavera, en un movimiento cíclico. De ahí que en el siguiente verso se diga: «Ruleta del azar y de las temporadas». Y más adelante, en el mismo poema, continúa el proceso de suma de imágenes sorprendentes: «Yo amo el buen tiempo y el hotel / y yo he visto mujeres de rizos calcinados / Las olas las rociaban de espumas de cocktail» (Ibíd). O sea, con el bien tiempo me gusta frecuentar los hoteles en los que he visto mujeres como si tuviesen rizos calcinados por el efecto ondulador de las tenacillas calientes, que luego templaban con las olas del mar, cuya espuma parecida a la empleada en los cocktails, actuaba como extintor de calor. Ofrezcamos un último ejemplo de otra composición («Ventana»): «Yo soy el pianista otoñal / Yo abro y cierro la noche como un libro / e interpreto la música de mi cielo manual» (Id: 119). Aquí el poeta es un pianista que en otoño abre y cierra la velada nocturna, al igual que hace con el librillo de partituras que, en realidad, es la poesía que escribe en su cuaderno durante la noche. 
Este proceso de yuxtaposición de elementos dispares, caracterizador del cubismo sintético, se manifiesta en la estructura del poema en un encadenamiento de imágenes que recorren el espacio textual y proporcionan el movimiento circular tan querido por los cubistas. Por ejemplo, en el poema «Rosa mística» (Imagen: 157) se lee:

$\begin{array}{ll}\text { Anidaba en sus ojos } & \\ \text { y en su cabellera } & \text { el ave maría } \\ \text { Era ella } & \text { se trenzaban las letanías } \\ & \text { Era ella }\end{array}$

La imagen «anidaba en sus ojos» genera la siguiente: «el ave maría» y este nombre femenino el verso siguiente: «Y en su cabellera», de donde nace la noción de trenzar, cuyo sujeto remite a la Virgen, a la que se hace referencia, a modo de letanía, en la repetición del sintagma «era ella». Además, la cadena de imágenes que hablan del trenzado se apoya en una disposición tipográfica que sugiere esta forma.

En el poema «Tren» (Id: 166), de la imagen inicial «cada estación es un poco nido» parte la visión de la pareja que se separa

\section{como dos \\ golondrinas paralelas}

La aparición de estas aves determina, al mismo tiempo, el recuerdo de una bandada de pájaros, que, en este caso, son estrellas, que, como las palomas, el poeta quiere que sean mensajeras: «Y arriba una bandada de estrellas mensajeras» (Ibíd).

En «Círculo» (Id: 175) la vivencia cotidiana de algo percibido como un ruido ( «Este recóndito fastidio / anida todos los años en mi oído») da lugar a la imagen de una máquina inútil («Y de este motor que nada mueve») que lanza un sonido de insecto («siempre zumbando su estribillo agreste»), concretado más adelante en las abejas. Estas, pues, representan las horas del reloj despertador («este motor que nada mueve») que, como el paso del tiempo, van consumiendo al poeta:

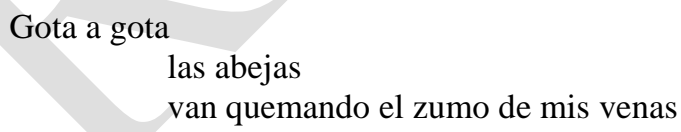

(Ibíd)

Por otra parte, en el poema «Cartel» (Id: 196), título que alude a un formato que permite la forma de percepción rápida y simultánea buscada por los cubistas, se dice:

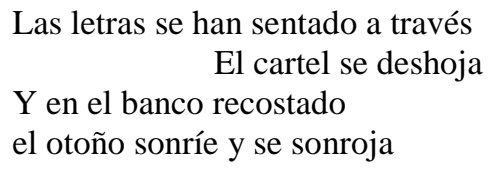


La imagen de las letras sentándose origina la siguiente: «El cartel se deshoja», y esta, por la polisemia del término (desprenderse las hojas de un libro o caerse las de un árbol), la del otoño. Éste, a su vez, aparece recostado por un procedimiento de personificación y de síntesis: alude a la caída de las hojas sobre los bancos y también al deterioro del cartel en el que, el arrugarse -acción irónicamente sugerida en las isotopías fónicas finales-, parecen agacharse las letras.

En Manual de espumas hallamos asimismo esta concatenación de imágenes. En el poema que abre el poemario, «Primavera» (Manual: 77-78), la imagen de la naturaleza que se despierta («Ayer... Mañana / Los días niños cantan en mi ventana») se concreta en el canto de los niños, que remite a las golondrinas, que volando en círculos - de ahí las expresiones «y van y vienen las golondrinas / doblando y doblando esquinas»- aparecen en la imagen siguiente: «violadores de rosas / Gozadores perpetuos del marfil de las cosas». Luego, a través de la imagen de nido, se funden imágenes heterogéneas que terminan en una repetición a modo de estribillo «la sombra verde de mi amor». Al final se retoma el título, ratificando su carácter de génesis, («La primavera nace / y en su cuerpo de luz la lluvia pace») y de renovación («el arco iris brota de la cárcel») que, en última instancia, remiten al principio creador de la poesía: «Y sobre los tejados / mi mano blanca es un hotel / para palomas de mi cielo infiel».

Se trata, en fin, de fundir varios temas en una sola composición poética. Es un recurso que también hallamos en otros textos. En «Otoño» (Id: 91) la asociación de la mujer y el paso del tiempo desencadena ricas imágenes: «Mujer densa de horas / y amarilla de frutos / como el sol del ayer»o «El reloj de los vientos te vio florecer / cuando en su jaula antigua / se arrancaba las plumas el terco atardecer». Esta última imagen del paso del tiempo originará la siguiente: «El reloj de los vientos / despertador de pájaros pascuales» y así prosigue el poema enlazando imágenes de los dos temas elegidos.

Lo mismo sucede en «Adiós» (Id: 102-103), de clara semejanza con el anterior y en «Novela» (Id: 104-105), donde la tarea de la policía se enreda con la descripción de los fenómenos de la naturaleza y del escenario urbano. En otros momentos la realidad artística se divide en múltiples elementos a los que el título proporciona una unidad y coherencia. Es el caso de «Mirador» (Id: 7980), «Aldea» o «Panorama» (Id: 107), en los que se crea una atmósfera con diferentes visiones recortadas de la realidad.

En cualquier caso, el poeta no reproduce el entorno, sino que, como sucedía en el cuadro cubista, crea su propio mundo y nos lo presenta como una construcción nueva, en la que la yuxtaposición de imágenes, configurada con elementos dispares, a la manera del 'collage', y distribuidas en la poesía según principios geométricos y de simultaneísmo, convierten el poema en una realidad en sí misma. Para ello nuestro escritor utiliza los recursos que hemos señalado a lo largo de este trabajo y que constituyen un intento de traducir la técnica practicada por Picasso, Braque y, sobre todo, por Juan Gris en el cubismo sintético. 
La simultaneidad espacial en la poesía cubista de Gerardo Diego

\section{Referencias bibliográficas}

Alonso, D. (1969): Poetas españoles contemporáneos, Madrid, Gredos.

CAno Ballesta, J. (1998): «Pasión y "línea pura": Gerardo Diego y el cubismo», en F. J. DíEZ DE

Revenga, F. J. y M. De PACO, M., eds.: En círculos de lumbre. Estudios sobre Gerardo Diego. Murcia, Caja de Murcia. Obra cultural, pp.153-172.

Colvile, G. M. M. (1977): Vers un langage des arts autour des années vingts. París, Librairie C. Klincksieck.

De Costa, R. (1993): «Posibilidades creacionistas: Gerardo Diego», en J. L. BERnAL, ed., Gerardo Diego y la vanguardia hispánica. Universidad de Extremadura, pp. 11-24.

DE MiCHELI, M. (1959): Las vanguardias artísticas del siglo XX. Madrid, Alianza, 1988.

DiEGO, G. (1922): Imagen. Málaga, Centro Cultural de la Generación del 27, 1990.

(1924): Manual de espumas. Versos humanos. Madrid, Cátedra, 1986.

(1974): Poesía de creación. Barcelona, Seix Barral.

Gleizes, A y Metzinger, J. (1912): Du «cubisme». París, Eugène Figuière éditeurs.

GoldinG, J. (1959): El cubismo: una historia y un análisis, 1907-1914. Madrid, Alianza forma, 1993.

GuINEY, M. (1966): Cubisme et littérature, Georg, Genève.

HADERMANN, P. (1984): «Cubisme», en J. WeISGERBER, J., coord., Les avant-gardes littéraires au XXe siècle, vol. II. Budapest, Académiai Kiadó, pp. 944-963.

Hermosilla Álvarez, C. (1990): «La escritura como elemento del cuadro», Cuadernos de Filología Francesa, 4, pp. 67-80.

Hermosilla Álvarez, M.A. (1996): «La poésie cubiste de Gerardo Diego: un exemple», en M.

PRUDON, coord., Peinture et écriture. París, La Différence (UNESCO), pp. 163-172.

- (2011): «Procedimientos visuales en la teoría hermenéutica de Wolfgang Iser», Ámbitos. Revista de Estudios de Ciencias Sociales y Humanidades, 25, pp. 21-31.

Husserl, E. (1950): La idea de la Fenomenología. México/Madrid, Fondo de Cultura Económica, 1997.

KAHNWEILER, D.-H. (1946): Juan Gris sa vie, son oeuvre, ses écrits. París, Gallimard, col. Folio/essais.

KANIZSA, G. (1980): Gramática de la visión: percepción y pensamiento. Barcelona, Paidós, 1986.

LÓPEZ MARTíneZ, M. I. (1988): «Valores gráficos del verso libre en el grupo del 27» (I), Anuario de Estudios Filológicos, XI, pp. 231-251.

_ (1989), «Valores gráficos del verso libre en el grupo del 27»(II), Anuario de Estudios Filológicos, XII, pp. 145-170.

Orlandi CEREnZA, G. (1982): Cubismo letterario. Roma, Lucarini editore.

REVERDI, P. (1918): «L’image», Nord-Sud. Revue littéraire, 13.

VERHESEN, F. (1984): «La poésie», en J. WEISGERBER, J., coord., Les avant-gardes littéraires au XXe siècle, vol. II. Budapest, Académiai Kiadó, pp. 798-824. 